\title{
Total endovascular treatment for extent type 1 and 5 thoracoabdominal aortic aneurysms
}

\author{
Gabriele Piffaretti, MD, PhD, ${ }^{\mathrm{a}}$ Federico Fontana, MD, ${ }^{\mathrm{b}}$ Marco Franchin, MD, ${ }^{\mathrm{a}}$ Alessandro Bacuzzi, MD, \\ Walter Dorigo, MD, ${ }^{\mathrm{d}}$ Patrizio Castelli, MD, ${ }^{\mathrm{a}}$ and Matteo Tozzi, $\mathrm{MD}^{\mathrm{a}}$
}

\section{ABSTRACT}

Objective: The study objective was to describe the results of thoracic endovascular aortic repair with the intentional coverage of the celiac artery and distal supramesenteric landing zone for extent type 1 and type 5 thoracoabdominal aortic aneurysms.

Methods: Inclusion criteria were thoracic endovascular aortic repair with celiac artery coverage to treat elective or urgent extent type 1 and 5 thoracoabdominal aortic aneurysms. Primary end points were in-hospital and follow-up survival, freedom from aortic-related mortality, and freedom from reintervention.

Results: Thoracoabdominal disease extent was type 1 in 12 patients $(71 \%)$ and type 5 in 5 patients $(29 \%)$. Urgent repair was performed in 4 patients $(23.5 \%)$. Primary technical success was $100 \%$. Early mortality and visceral ischemia did not occur. Permanent spinal cord ischemia rate was $6 \%(n=1)$. Follow-up ranged from 3 to 120 months (interquartile range, 12-36.5). Survival estimate was $85 \% \pm 9 \%(95 \%$ confidence interval, 67-94) at 1 year and $49 \% \pm 17 \%$ $(95 \%$ confidence interval, 21-78) at 5 years. Cumulative freedom from aortic-related mortality was $94 \%$, and estimated freedom from reintervention at 1 and 5 years was 93\% $\pm 7 \%$ (95\% confidence interval, 68-99). Neither type 1 endoleaks nor distal stent-graft migration causing superior mesenteric artery occlusion was detected.

Conclusions: Thoracic endovascular aortic repair with intentional coverage of celiac artery for extent 1 and 5 thoracoabdominal aortic aneurysms had satisfactory results in selected patients at high risk for open repair. Visceral ischemia did not occur, but spinal cord ischemia is still high at $6 \%$. At midterm follow-up, neither endoleak development nor aortic reintervention was related to the inadequate distal landing zone. Follow-up survival is satisfactory and comparable to open repair. (J Thorac Cardiovasc Surg 2017;154:1487-96)

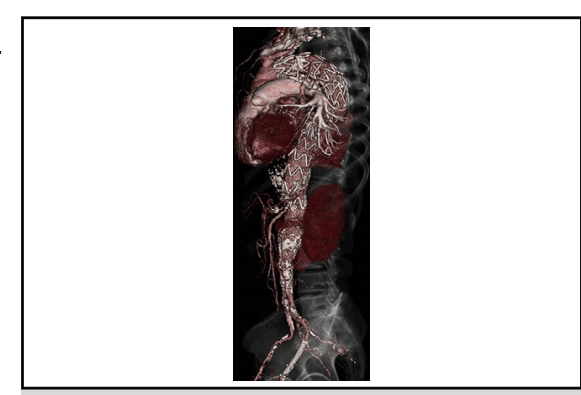

Total endovascular repair for Crawford extent 1 TAAA.

Central Message

TEVAR with intentional coverage of the CA for extent 1 and 5 TAAAs had results comparable to those for conventional OR.

\section{Perspective}

Visceral involvement of the aneurysmal disease often is a prohibitive factor for TEVAR using standard SG because of the proximity of the mesenteric circulation. In selected cases, TEVAR using standard SG with the coverage of the CA may be a viable technique for patients who may not tolerate complex and risky OR.

See Editorial Commentary page 1497.
Thoracic endovascular aortic repair (TEVAR) has demonstrated better results than open repair (OR) for descending thoracic aortic aneurysms. ${ }^{1}$ However, the visceral involvement of the aneurysmal disease often is a prohibitive

\footnotetext{
From ${ }^{a}$ Vascular Surgery, ${ }^{\mathrm{b}}$ Interventional Radiology, and ${ }^{\mathrm{c}}$ Anesthesia and Palliative Care, Department Medicine and Surgery, Circolo University Teaching Hospital, University of Insubria School of Medicine, Varese, Italy; and ${ }^{\mathrm{d}}$ Vascular Surgery, Department of Cardiothoracic and Vascular Surgery, Careggi University Teaching Hospital, University of Florence School of Medicine, Florence, Italy.

Received for publication Dec 5, 2016; revisions received March 21, 2017; accepted for publication April 21, 2017; available ahead of print Aug 14, 2017.

Address for reprints: Gabriele Piffaretti, MD, PhD, Vascular Surgery, Department of Surgery and Morphological Sciences, Circolo University Teaching Hospital, University of Insubria School of Medicine, Via Guicciardini, 9, 21100 Varese, Italy (E-mail: gabriele.piffaretti@uninsubria.it).

$0022-5223 / \$ 36.00$

Copyright (c) 2017 by The American Association for Thoracic Surgery http://dx.doi.org/10.1016/j.jtcvs.2017.04.067
}

factor for TEVAR using a standard stent-graft (SG) because of the proximity of the mesenteric circulation and anatomically inadequate distal sealing zone. Only few centers of excellence have published acceptable operative mortality rates less than $10 \%$ after OR for thoracoabdominal aortic aneurysms (TAAAs) (T) $^{-4}$ in the "real world" practice, OR for TAAAs is still plagued by a mortality rate up to $22 \% .^{5}$

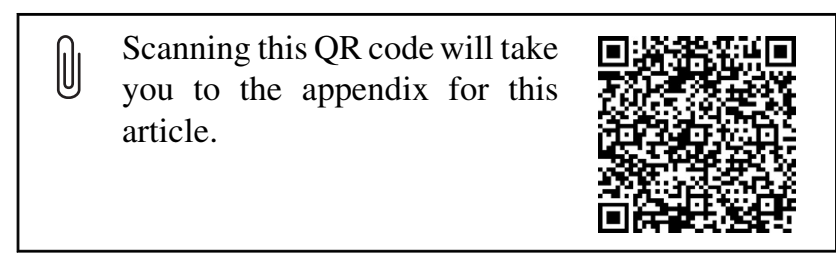




$$
\begin{aligned}
& \text { Abbreviations and Acronyms } \\
& \begin{aligned}
\text { ARM } & =\text { aortic-related mortality } \\
\text { CA } & =\text { celiac artery } \\
\text { CI } & =\text { confidence interval } \\
\text { CSFD } & =\text { cerebrospinal fluid drainage } \\
\text { CTA } & =\text { computed tomography angiography } \\
\text { IQR } & =\text { interquartile range } \\
\text { OR } & =\text { open repair } \\
\text { SCI } & =\text { spinal cord ischemia } \\
\text { SG } & =\text { stent-graft } \\
\text { SMA } & =\text { superior mesenteric artery } \\
\text { SVS } & =\text { Society for Vascular Surgery } \\
\text { TAAA } & =\text { thoracoabdominal aortic aneurysm } \\
\text { TEVAR } & =\text { thoracic endovascular aortic repair }
\end{aligned}
\end{aligned}
$$

Hybrid reconstructions, TEVAR with fenestrations, or parallel-graft techniques have been used as alternative techniques especially for patients at high risk for OR, but even these are physically and technically demanding procedures or still have unproven durable long-term results. ${ }^{6,7}$ Total visceral reconstruction (open, hybrid, endovascular with fenestrations) is unavoidable in most TAAAs: however, in extent type 1 and type 5, TEVAR using standard SG with the coverage of the celiac artery (CA) can be a less complex and strenuous procedure. $^{8-11}$

The aim of this article was to report our results with total endovascular repair of extent type 1 and type 5 TAAAs using standard TEVAR with the intentional coverage of the CA and supramesenteric distal landing zone.

\section{MATERIALS AND METHODS \\ Study Design and Cohort of Patients}

This is a single-center, observational descriptive study. Starting in June 2006, all patients treated with TEVAR for TAAA were identified (Figure 1). For the final analysis, the end of the study was December 1, 2016.

The present cohort includes the following:

- TEVAR with coverage of the CA to treat elective (diameter $\geq 60 \mathrm{~mm}$ ) or urgent extent type 1 and type 5 TAAAs in patients considered unfit for OR.

The cohort does not include the following:

- TEVAR with CA coverage to treat elective or urgent saccular juxtaceliac aortic lesions;

- distal SG extension with CA coverage to treat elective or urgent type $1 \mathrm{~b}$ endoleak;

- TAAA treated with OR or hybrid reconstruction (TEVAR with retrograde visceral vessels revascularization); and

- TAAA treated with branched/fenestrated SG, or with ancillary techniques such as chimney/snorkel/periscope.

All clinical and procedural data were prospectively collected and recorded into a computerized database. Information about demographics, comorbidities, medical and surgical history, operative details and postoperative events during the hospital stay, and follow-up was registered.
Informed consent was signed by all patients. Approval for this specific study was obtained by the local Institutional Review Board according to the National Policy in the matter of Privacy Act on retrospective analysis of anonymized data.

\section{Aortic Assessment, Treatment Protocol, and Follow-up}

This type of TEVAR was performed if the distal SG landing zone was less than $41 \mathrm{~mm}$ in diameter and $10 \mathrm{~mm}$ at least in length from the origin of the superior mesenteric artery (SMA) (Figure 2, A-C). Meticulous attention was paid to evaluate the mesenteric circulation: Both the SMA and the portal vein had to be patent. Thus, exclusion criteria were morphologic and clinic-pathologic:

- aortic disease extent involving both the CA and the SMA;

- larger (>41 mm) aortas;

- SMA occlusion or signs/symptoms of abdominal angina, or portal vein occlusion; and

- chronic dissection with very narrowing true lumen.

For the gastroduodenal collateral network between the SMA and the CA, a preoperative selective arteriogram was eventually performed using the temporary CA balloon occlusion test to further delineate the existence of these collaterals when computed tomography angiography (CTA) did not elucidate them clearly. ${ }^{12,13}$ Triple-phase CTA followup was performed at 1,6 , and 12 months, and on an annually basis thereafter (Figure 3, A, B, C1-2). Maximum aortic diameter was measured on preoperative CTA and on the most recent postoperative CTA.

\section{Operative Technical Details}

All operations were performed in the operating room, using general anesthesia in all patients. According to the cardiovascular risk of the patient, general anesthesia was performed using midazolam 0.01 to $0.1 \mathrm{mg} / \mathrm{kg}$, propofol 1 to $2 \mathrm{mg} / \mathrm{kg}$ or thiopental sodium 2 to $4 \mathrm{mg} / \mathrm{kg}$, fentanyl 1 to $2 \gamma / \mathrm{kg}$, and rocuronium 0.6 to $1.2 \mathrm{mg} / \mathrm{kg}$. General anesthesia was maintained using halogenated gases. The management of spinal cord ischemia (SCI) prevention involved different aspects, which are in agreement with the most recent position statement of the European Association for Cardio-Thoracic Surgery vascular domain. ${ }^{14}$ Briefly, in elective cases, antiplatelets and anticoagulants were suspended appropriately to limit the bleeding risk for cerebrospinal fluid drainage (CSFD) positioning. The CSFD catheter was inserted intraoperatively and maintained for at least 72 hours. Left subclavian artery revascularization was performed in the presence of a stable clinical condition, when the dominant left vertebral artery had been confirmed, or in the presence of previous abdominal aortoiliac surgery, patent arteriovenous access for hemodialysis, patent left internal thoracic artery in patients already submitted to coronary artery bypass grafting, and left arm ischemia/impotence. A combination of vasoactive agents infusion (dopamine, 3-5 $\mathrm{\gamma} / \mathrm{kg} / \mathrm{min}$, noradrenaline 0.01-0.1 $\mathrm{\gamma} / \mathrm{kg} / \mathrm{min}$, nitroglycerin $0.5-5 \gamma / \mathrm{kg} / \mathrm{min}$ ), fluid intake, and diuretics (bolus of furosemide $10-20 \mathrm{mg}$ or $50-150 \mathrm{mg} / \mathrm{die}$ of mannitol $5 \%$ infusion) was used to maintain a stable hemodynamic condition throughout the entire procedure, and the postoperative course: Mean arterial pressure was maintained at $80 \mathrm{~mm} \mathrm{Hg}$ or greater, central venous pressure was maintained at less than $12 \mathrm{~mm} \mathrm{Hg}$, and transfusions were used to preserve hemoglobin level $10 \mathrm{~g} / \mathrm{dL}$ or greater. Generally, SGs were deployed sequentially: the longest possible SG proximally and the shorter one distally, to have the best deployment control as possible at the SMA border. CA occlusion was always performed before the deployment of the distal SG. In all patients, we used an endovascular plug that was delivered through the transfemoral approach. Both the SG and the endovascular plug were oversized by $20 \%$, according to the diameter of the normal 


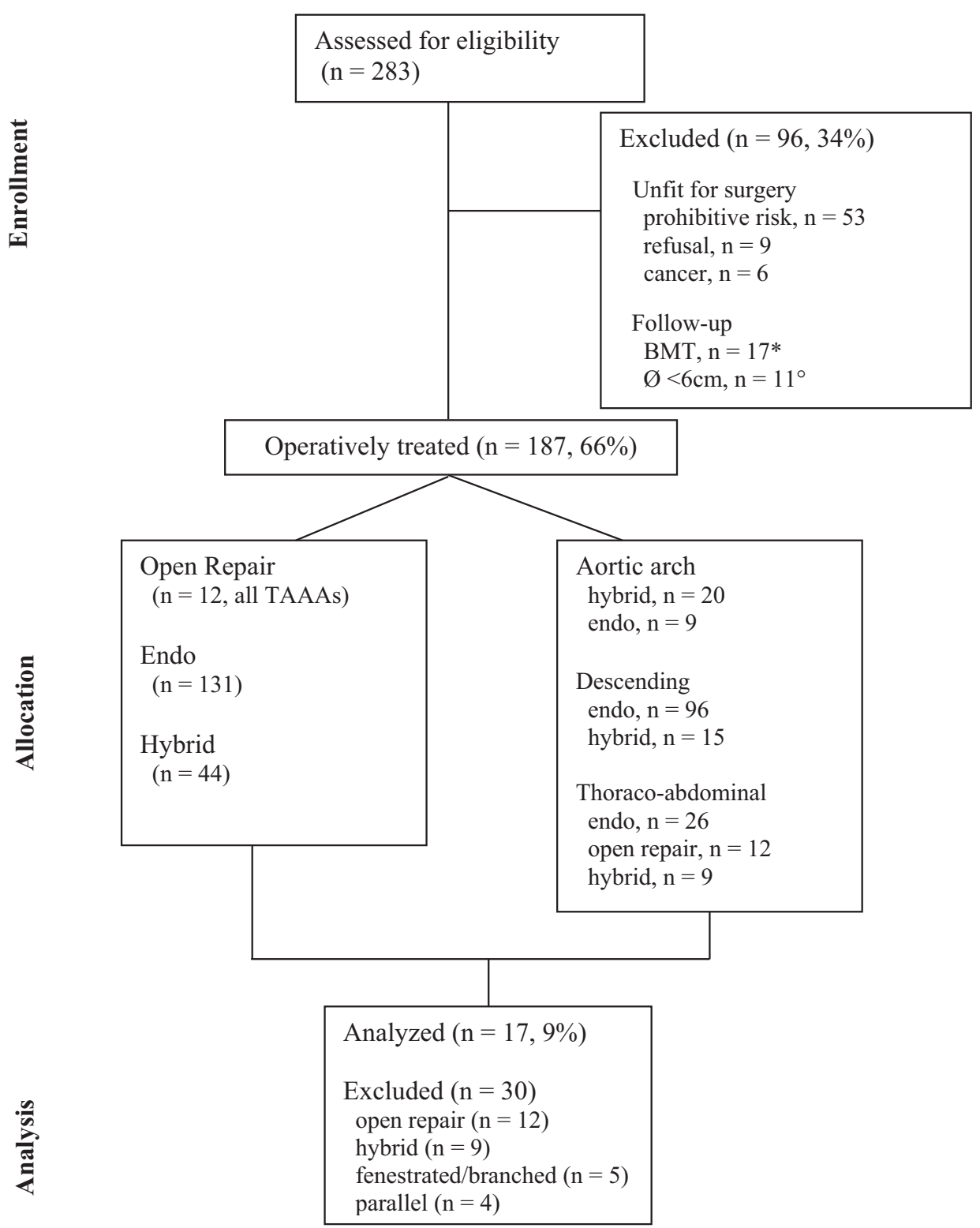

FIGURE 1. CONSORT diagram indicating all patients with descending and thoracoabdominal aneurysms during the period of study, including the patient population from whom this series was derived. BMT, Best medical treatment; TAAA, thoracoabdominal aortic aneurysm.

aorta at the landing zones and the diameter of the CA, respectively. All patients were admitted to the intensive care unit postoperatively. Laboratory analyses included blood count, coagulation serum lactic acid concentration, and full hepatic function panel on a daily basis. Graft materials are reported in the Appendix.

\section{Definition}

Comorbidities were defined according to the Society of Thoracic Surgeons adult database. ${ }^{15}$ Morphologic characteristics and outcomes were defined accordingly to the European Association for Cardio-Thoracic Surgery/European Society for Cardio-Vascular Surgery best practice guidelines for reporting treatment results in the thoracic aorta or the Society for Vascular Surgery (SVS) ad hoc committee on TEVAR reporting standards. ${ }^{16,17}$ In particular, urgency of the intervention was defined accordingly to the European System for
Cardiac Operative Risk Evaluation classification. ${ }^{18}$ Primary technical success was defined as the successful deployment of the SG with the exclusion of the aortic lesion in the absence of surgical conversion to OR or death at 24 hours or less. SCI was classified accordingly to the SVS grading system. ${ }^{16}$ The proximal landing zone of the thoracic SG was defined following the "arch map" classification. ${ }^{16}$ Follow-up index described follow-up completeness at the given study end date as the ratio between the investigated and the potential follow-up period. ${ }^{19}$ TEVAR-related mortality included deaths due to aortic rupture, surgical conversion, or complications of TEVAR unsolved by additional procedures. Aneurysm sac shrinkage was defined as $1 \mathrm{~cm}$ or greater maximum aortic diameter reduction from the preoperative measurement. Our analysis evaluated in-hospital mortality and follow-up survival, freedom from aortic-related mortality (ARM), and freedom from reintervention. 


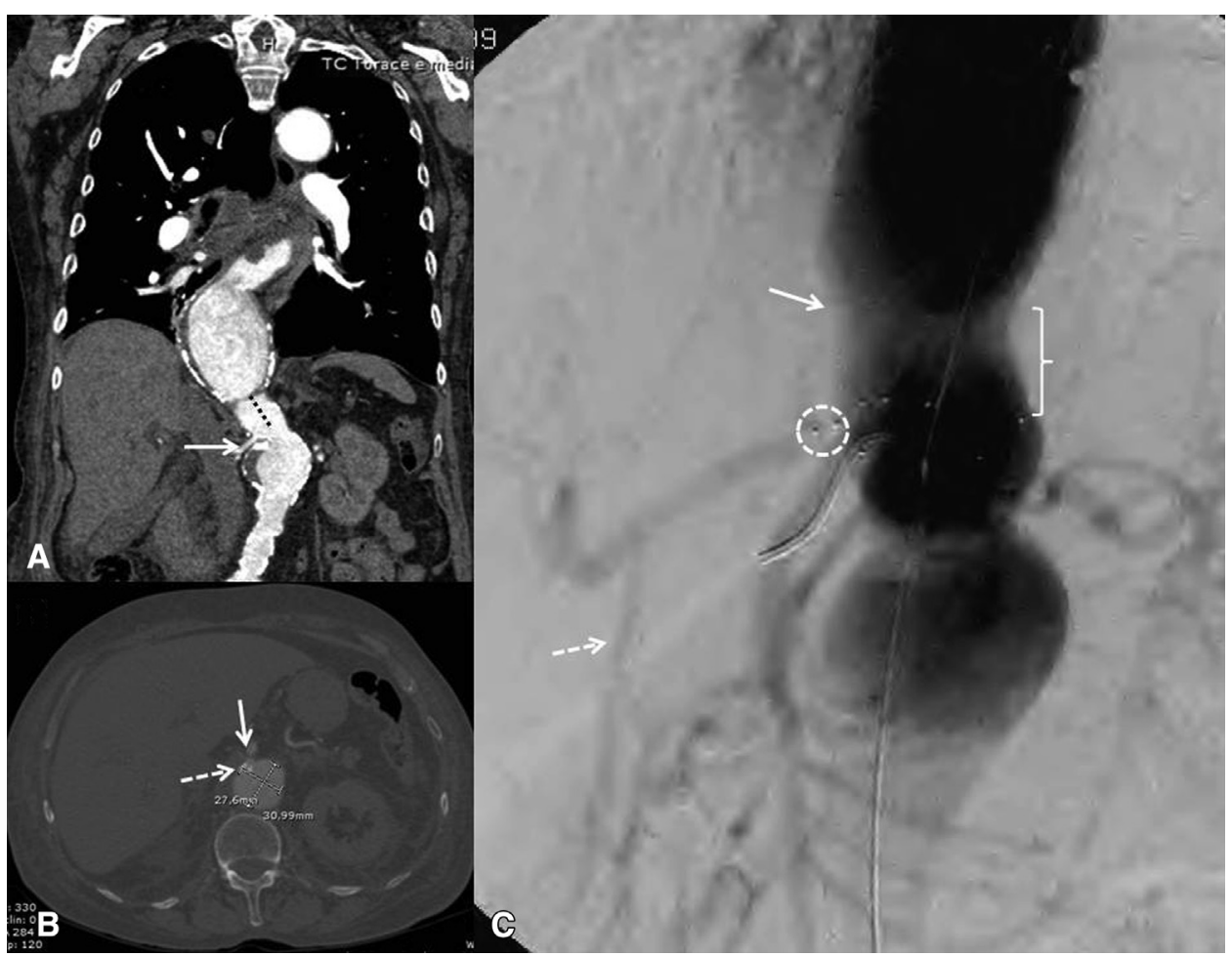

FIGURE 2. Preoperative CTA of a Crawford type 1 TAAA: Multiplanar reconstruction (A) shows the length (black dashed line) of the distal landing zone (arrow) at the supramesenteric artery. Axial CTA (B) shows the sizing at distal landing zone. Intraoperative completion angiogram (C) shows the additional $(14 \mathrm{~mm})$ tapered distal neck (brace) gained with the intentional coverage of the origin of the CA with the endovascular plug (dashed circle). In this case, the take-off of the CA was located at the transition point of the tapered area (arrow) at the final angiogram. Final angiogram also confirms the revascularization of the common hepatic artery through the collateralization of the SMA (dashed arrow).

\section{Statistical Analysis}

Clinical data were prospectively recorded and tabulated in Microsoft Excel (Microsoft Corp, Redmond, Wash) database. Statistical analysis was performed with SPSS, release 23.0 for Windows (IBM SPSS Inc, Chicago, Ill). Categoric variables were presented using frequencies and percentages, and continuous variables were presented with mean \pm standard deviation and interquartile range (IQR); otherwise, medians with range were applied. Wilcoxon signed-rank test was used to evaluate the difference in blood test results before and after TEVAR. Cumulative survival, freedom from ARM, and freedom from reintervention rates were estimated using the Kaplan-Meier method \pm standard error and $95 \%$ confidence interval $(\mathrm{CI})$.

\section{RESULTS}

\section{General Population and Cohort Data}

During the study period, we evaluated 283 patients with arch/descending/thoracoabdominal aortic disease. Of this cohort, 47 patients $(17 \%)$ had a TAAA: Total endovascular repair using TEVAR with intentional coverage of the CA was performed in 17 patients (overall TEVAR $=10 \%$; overall TAAAs $=36 \%$ ). Of these 17 TAAAs, 16 were degenerative atherosclerotic aneurysms and 1 was dissection-related aneurysm. No connective tissue disorder-related aneurysm was treated. During the same period, the remainder of TAAAs were treated with OR $(\mathrm{n}=12,25 \%)$, hybrid reconstruction $(\mathrm{n}=9,19 \%)$,
SG with branch/fenestrations ( $\mathrm{n}=5,11 \%)$, and chimney/ periscope $(n=4,8.5 \%)$. Three patients with extent type 1 or 5 did not undergo operation because of prohibitive operative risk (free rupture in octogenarian $n=2$, cancer $\mathrm{n}=1)$. We treated 9 women $(53 \%)$; overall, patients' mean age was $74 \pm 7$ years (range, 59-86; IQR, 69-79). Demographics, comorbidities, and risk factors are reported in Table 1. Thoracoabdominal disease extent was type 1 in 12 patients $(71 \%)$ and type 5 in 5 patients $(29 \%)$. The CA was patent in all cases, but $4(24 \%)$ had a preocclusive ostial stenosis; 13 patients $(76 \%)$ had a complete CA in the form of a gastro-hepato-splenic trunk, and 2 patients $(12 \%)$ had the right hepatic artery arising from the SMA. Adequate collateral network was present in all patients. The mean diameter of the distal sealing zone at the origin of the SMA was $31 \pm 6.5 \mathrm{~mm}$ (range, $25-40 \mathrm{~mm}$; IQR, 25-36). By covering the CA origin, we obtained a mean sealing zone of $18 \pm 8 \mathrm{~mm}$ (range, $10-32 \mathrm{~mm}$; IQR, 12-20).

\section{Operative Details}

Urgent repair was performed in 4 patients $(23.5 \%)$ because of thoracic pain and signs of impending rupture at CTA $(n=2)$ or contained rupture $(n=2)$. Intraoperative 


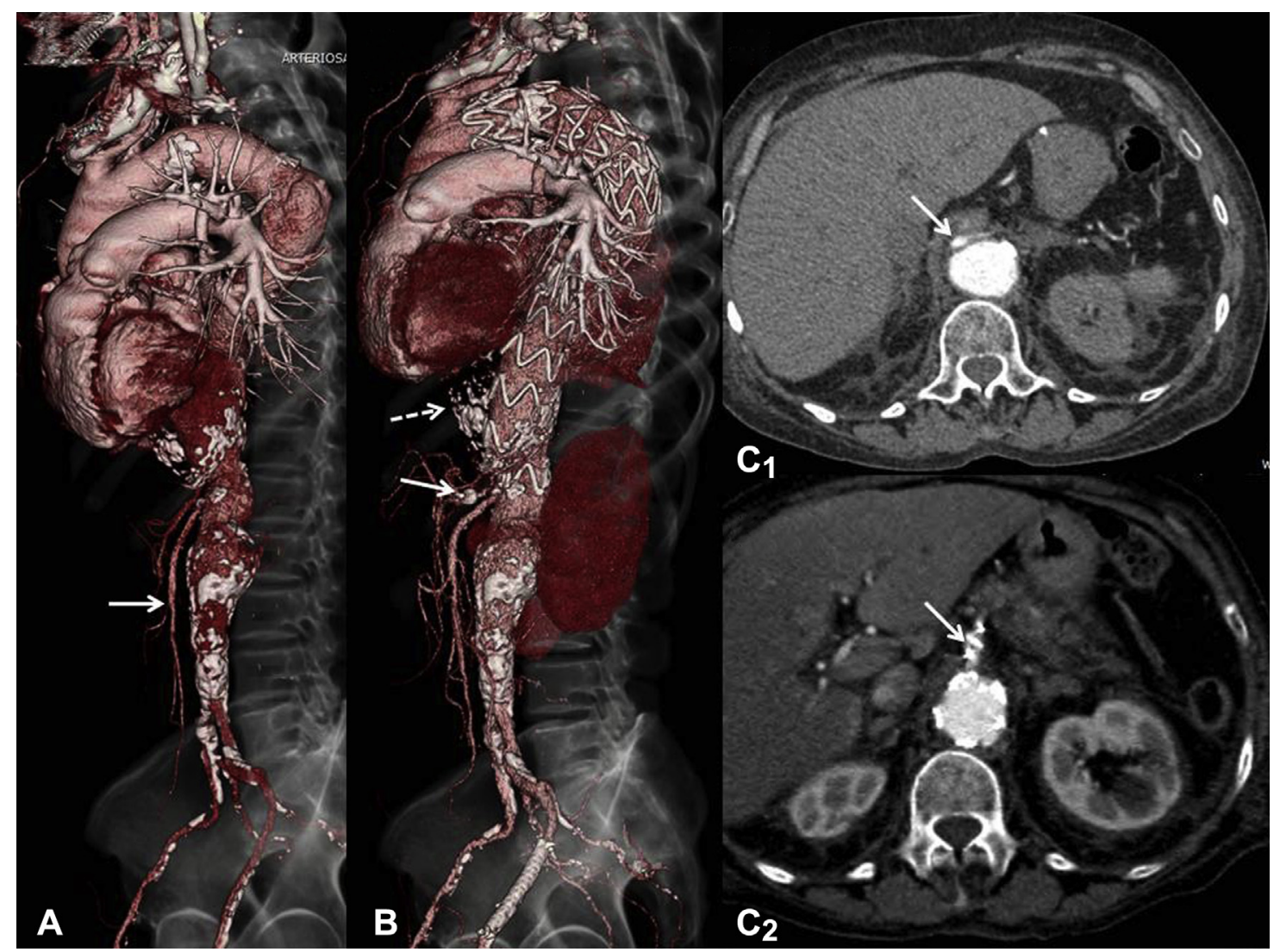

FIGURE 3. Preoperative (A) CTA with volume-rendering 3-dimensional reconstruction of a type 1 thoracoabdominal aortic aneurysm. Postoperative (B) follow-up CTA: thoracoabdominal TEVAR with intentional coverage of the CA. Note the patency of the CA (A, $\mathrm{C}_{1}$, arrow), its occlusion (B, $\mathrm{C}_{2}$, arrow) with the endovascular plug, and the absence of type $1 \mathrm{~b}$ endoleak (B, dashed arrow).

technical details are shown in Table 2. Briefly, CSFD was inserted in all elective cases; the left subclavian artery was revascularized in 3 patients (18\%) using a bypass graft from the left common carotid artery. We used only 1 vascular plug in each patient to occlude the CA. The mean oversizing at the distal landing zone was $22 \% \pm 4 \%$ (range, 15-30; IQR, 20-22).

\section{Early Results}

Primary technical success was $100 \%$; conversion to OR was never required. In-hospital mortality did not occur. Occlusion of the CA was successful in all cases, along with the exclusion of the TAAA. At final angiogram, there were no type 1 or type 2 endoleaks from the CA, and the SMA did not present filling defects. In all cases, adequate collateralization was observed in the final angiogram. All patients but $1(94 \%)$ were extubated at the end of the intervention; median intensive care unit stay was 1 day (range, 1-8; IQR, 1-4.5). Blood panel showed significant modifications between the preoperative and postoperative values, as reported in Table 3. No visceral ischemia requiring surgery occurred. Stroke was never observed. Postoperative complication developed in 3 patients
$(18 \%)$ : SVS class $3 \mathrm{c}$ SCI $(\mathrm{n}=1,6 \%)$, which did not respond to increase vascular perfusion and rehabilitation program; pneumonia $(\mathrm{n}=1)$, which was successfully treated with antibiotics; and atrial fibrillation $(\mathrm{n}=1)$, which resolved using amiodarone. Mean hospitalization was $11 \pm 8$ days (range, 4-29; IQR, 5-12).

\section{Late Outcomes}

All patients were discharged alive; 16 (94\%) were independently living at home. The mean follow-up was $36 \pm 25$ months (range, 3-120; median, 24; IQR, 12-36.5), and the follow-up index was $0.8 \pm 0.2$. All patients had CTA follow-up at 1 month, 12 patients $(70 \%)$ had CTA follow-up at 12 months, 7 patients (41\%) had CTA follow-up at 36 months or more, and 3 patients $(18 \%)$ had CTA follow-up at more than 60 months. During the follow-up, 6 patients ( $35 \%$ ) died after a median of 35 months (range, 4-96). Causes of late death are reported in Table 4. Kaplan-Meier estimate of survival was $85 \% \pm 9 \%(95 \% \mathrm{CI}, 67-94)$ at 1 year and $49 \% \pm 17 \%(95 \% \mathrm{CI}, 21-78)$ at 5 years (Figure 4$)$. Cumulative freedom from ARM was $94 \%$. A 73 -year-old extremely fragile woman developed an SG infection due 
TABLE 1. Demographic data, comorbidities, and risk factors

\begin{tabular}{lc}
\hline \multicolumn{1}{c}{ Variables } & $\mathbf{n}(\%)$ \\
\hline Demographics & $9: 8$ \\
F:M & $74 \pm 7(\mathrm{IQR}, 69-79)$ \\
Age, y (mean $\pm \mathrm{SD})$ & \\
Comorbidities & $17(100)$ \\
Hypertension & $13(76)$ \\
Dyslipidemia & $9(53)$ \\
COPD & $4(23.5)$ \\
AAA & $3(18)$ \\
AoS & $3(18)$ \\
Atrial fibrillation & $2(12)$ \\
Obesity $\left(\right.$ BMI $\left.>30 \mathrm{~kg} / \mathrm{m}^{2}\right)$ & $2(12)$ \\
Renal insufficiency & \\
(eGFR $<30 \mathrm{~mL} / \mathrm{min})$ & $2(12)$ \\
CVA & $2(12)$ \\
Diabetes & $2(12)$ \\
Ischemic heart disease &
\end{tabular}

\section{Risk factors}

$\begin{array}{lc}\text { Diameter }(\mathrm{mm} \pm \mathrm{SD}) & 72 \pm 0.9(\mathrm{IQR}, 6.5-7.8) \\ \text { Rupture } & 2(12)\end{array}$

Arch atheroma

$\begin{array}{ll}\text { Absent } & 6(35) \\ \text { Protruding }<5 \mathrm{~mm} & 8(47) \\ \text { Protruding }>5 \mathrm{~mm} & 3(18)\end{array}$

or "shaggy" aorta

euroSCORE additive (mean $\pm \mathrm{SD}$ )

$11.4 \pm 3(\mathrm{IQR}, 9-13)$

euroSCORE logistic (mean \pm SD)

$30.5 \pm 17.2$ (IQR, 15.46-41.21)

euroSCORE II (mean $\pm \mathrm{SD}$ )

$6.7 \pm 5.3(\mathrm{IQR}, 3.4-6.82)$

$n$, Number; $F$, female; $M$, male; $S D$, standard deviation; $I Q R$, interquartile range; $C O P D$, chronic obstructive pulmonary disease; $A A A$, abdominal aortic aneurysm; $A o S$, previous aortic surgery; $B M I$, body mass index; $e G F R$, estimated glomerular filtration rate; CVA, cerebrovascular accident; euroSCORE, European System for Cardiac Operative Risk Evaluation.

to an aortoesophageal fistula 4 months after TEVAR. In this case, an esophageal SG was implanted to prevent massive fatal bleeding, but she died of sepsis shortly after this procedure. Estimated freedom from aortic-related events and reintervention at 1 and 5 years was $93 \% \pm 7 \%(95 \% \mathrm{CI}$, 68-99). Two events (12\%) occurred: the mentioned aortoesophageal fistula (at 4 months) and a type 3 endoleak (at 72 months) that was successfully sealed off with an additional SG. Sac shrinkage was observed in 10 patients $(59 \%)$. Both type 1 and type 2 endoleaks were not detected. SG infolding at the distal sealing zone or caudal SG migration causing SMA obstruction or abdominal angina was never observed.

\section{DISCUSSION}

Extent type 1 and 5 are not infrequent among all TAAAs. In large-volume aortic centers, the mean prevalence was $25 \%$ with a reported range of $23 \%$ to $37 \% .^{2-4,8}$ Surgical decision making is a key element in surgery, and thus any
TABLE 2. Technical details and intraoperative data

\begin{tabular}{lc}
\hline \multicolumn{1}{c}{ Variables } & $\mathbf{n}(\%)$ \\
\hline General anesthesia & $17(100)$ \\
Vascular access & $16(94)$ \\
Femoral & $1(6)$ \\
Iliac conduit & \\
SG & $4(23.5)$ \\
Distal free-flow & $29 \pm 7(\mathrm{IQR}, 24-35)$ \\
$\quad$ Aortic coverage (cm mean $\pm \mathrm{SD})$ & $14(82)$ \\
2 SGs & $3(18)$ \\
3 SGs & $13(76)$ \\
CSFD & $180 \pm 85(\mathrm{IQR}, 130-240)$ \\
\hline Duration (min mean \pm SD) & $231 \pm 159(\mathrm{IQR}, 100-412.5)$ \\
Blood loss (mL mean \pm SD) & $128 \pm 39(\mathrm{IQR}, 105-142.5)$ \\
Contrast (mL mean \pm SD) & \\
PRBC (units) & $6(35)$ \\
0 & $8(47)$ \\
$1-4$ & $3(18)$ \\
$\geq 4$ & $3(18)$ \\
Adjunctive procedures & $2(12)$ \\
Carotid-subclavian bypass & $2(12)$ \\
Iliac stent & $1(6)$ \\
Femoral endarterectomy + patch & $1(6)$ \\
Right renal stent & \\
EVAR & \\
\hline
\end{tabular}

$n$, Number; $S G$, stent-graft; $S D$, standard deviation; $C S F D$, cerebrospinal fluid drainage; $I Q R$, interquartile range; $P R B C$, packed red blood cell; $E V A R$, endovascular abdominal aortic repair.

type of intervention that may ameliorate outcomes after TAAA repair is welcome. There are 2 main reasons why we considered TEVAR with the intentional coverage of the CA a valid alternative especially for patients at high risk for OR: the mean mortality rate of $11 \%$ reported by centers of excellence after OR for type 1 and 5 TAAAs, and the encouraging results of the series that reported this specific TEVAR strategy. ${ }^{8-13,20-23}$

TABLE 3. Perioperative modifications of the blood panel

\begin{tabular}{lccc}
\hline & Preoperative & $\begin{array}{c}\text { Postoperative } \\
\text { (maximum level) }\end{array}$ & $\begin{array}{c}\boldsymbol{P} \\
\text { value }\end{array}$ \\
\hline WBC (cells/mm $\left.{ }^{3}\right)$ & $8334 \pm 2336$ & $12,456 \pm 5229$ & .002 \\
& $(\mathrm{IQR}, 6650-9230)$ & $(\mathrm{IQR}, 8945-13,385)$ & \\
GOT (U/L) & $20 \pm 7$ & $28 \pm 13$ & .054 \\
& $(\mathrm{IQR}, 16.5-22.5)$ & $(\mathrm{IQR}, 16.5-35.5)$ & \\
GPT (U/L) & $18 \pm 13$ & $32 \pm 22$ & .021 \\
& $(11-19.5)$ & $(13-52)$ & \\
LDH (U/L) & $301 \pm 140$ & $842 \pm 756$ & .002 \\
& $(\mathrm{IQR}, 188.3-392)$ & $(\mathrm{IQR}, 428-865.5)$ & \\
\hline Lactates (mmol/L) & $0.9 \pm 0.2$ & $1.2 \pm 0.2$ & .001 \\
& $(\mathrm{IQR}, 0.8-1)$ & $(\mathrm{IQR}, 1-1.2)$ & \\
\hline
\end{tabular}

$\overline{W B C}$, White blood cells; $I Q R$, interquartile range; GOT, glutamate oxaloacetate transaminase; $G P T$, glutamate pyruvate transaminase; $L D H$, lactic dehydrogenase. 
TABLE 4. Causes of mortality during the follow-up

\begin{tabular}{lccllc}
\hline Gender & Age & TAAA (extent) & PoC & Cause & POM (mo) \\
\hline M & 65 & 5 & Uneventful & AMI & 96 \\
F & 86 & 1 & Uneventful & AKI & 12 \\
M & 76 & 5 & Pneumonia & Traumatic cerebral hemorrhage \\
F & 73 & 1 & Uneventful & Sepsis & 36 \\
F & 71 & 1 & Uneventful & Colorectal cancer & 4 \\
M & 81 & 5 & Uneventful & Respiratory failure & 37 \\
\hline
\end{tabular}

TAAA, Thoracoabdominal aortic aneurysm; PoC, postoperative course; $P O M$, postoperative mortality; $M$, male; $A M I$, acute myocardial infarction; $F$, female; $A K I$, acute kidney injury.

A recent propensity-matched score analysis comparing TEVAR and OR for TAAAs reported an operative mortality in the range of $6.3 \%$ to $7.7 \% .{ }^{24}$ Such analysis did not stratify for TAAA extent; this is not an indifferent detail, and not only for OR. A recent publication by Schaffer and colleagues ${ }^{25}$ focusing on the use of TEVAR in different clinical scenarios showed that patients with more complex aortic disease required more complex procedures, with worse results. This means the simpler the procedure, the better the results. Although our series is a selected cohort of patients at high risk for OR, standard TEVAR with the intentional coverage of the CA brought satisfactory results if compared with the predicted $6.6 \%$ mortality rate.

Undeniably, there are important concerns regarding the outcomes of TEVAR for TAAAs. The first concern is aortic-related failures: The need for aortic reintervention was $12 \%$ in our experience, which is clearly higher than the $2.6 \%$ to $4.6 \%$ after OR reported in the largest experiences. ${ }^{2,4}$ After reviewing the literature data on TEVAR with intentional coverage of the CA, the need for
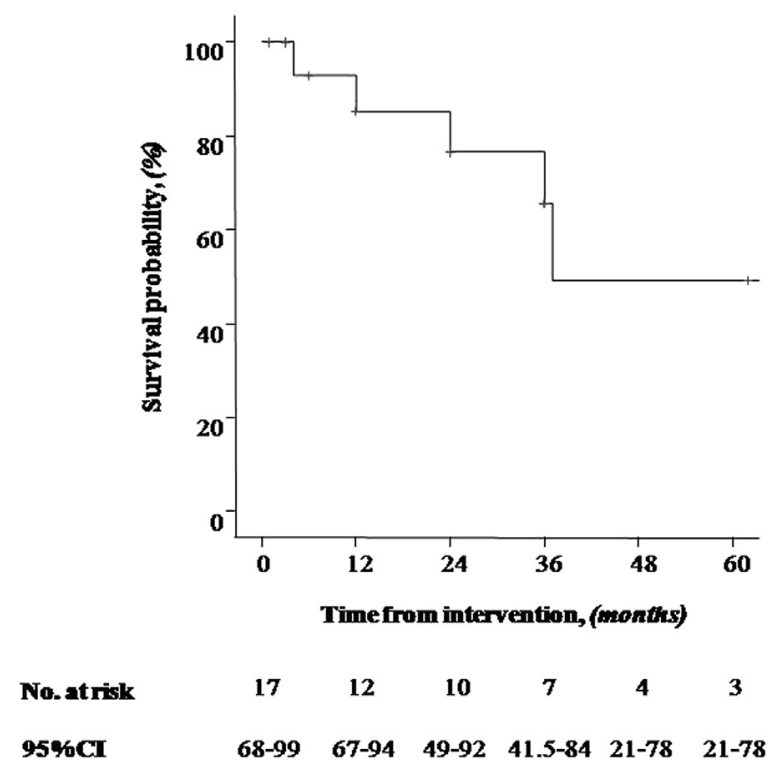

FIGURE 4. Kaplan-Meier graphs show the estimated survival in patients treated with TEVAR and intentional coverage of the CA for extent type 1 and type 5 thoracoabdominal aortic aneurysms. $C I$, Confidence interval. aortic reintervention was still high at $8.6 \%$ (Table 5). ${ }^{8-13,20-23}$ However, reintervention was always performed with another endovascular intervention, the redo-related operative mortality was absent, and reintervention did not influence follow-up survival..$^{8-13,20-23}$ Second, the primary goal of TEVAR is freedom from ARM. Our experience was not exempt from this risk, but the $94 \%$ cumulative freedom from ARM is satisfactory, especially if we take into account the advanced mean age and the high-risk profile for OR of this cohort. ${ }^{2-}$ 4,6,26 This is a result that finds support from Patel and colleagues, ${ }^{27}$ who reported a significant survival benefit of TEVAR versus OR for high-risk patients. Last, but not least, survival in the follow-up is a concern: Although the results are not robust enough to be considered long-term results, the estimated survival at 5 years of $49 \%$ is satisfactory for these high-risk patients if compared with the $47 \%$ reported in a large database analysis. ${ }^{25}$

When covering the CA to extend the distal sealing zone of TEVAR, visceral ischemia is an important concern..$^{22,28}$ Although in our review (Table 5) this complication was never reported in $63 \%$ of the series on TAAAs, when this occurred, mortality was ascribed to "shock liver." 13,20,22 We maintained an alert vigilance during the entire postoperative period for 2 main reasons: (1) the unpredictable occurrence and clinical manifestation of visceral ischemic complications and (2) the significant increase in the postoperative period of liver enzymes, white blood cells, and lactates, all potential markers of splanchnic ischemic hypoperfusion. These modifications did not develop homogeneously and did not have a consensual trend. Similar to previous experience, we were not able to identify cutoff values that would prompt emergency reintervention to prevent acute visceral complications. ${ }^{13,20}$ Although these remarkable blood test modifications did not translate into severe ischemic complications, we can draw 2 observations. On the one hand, they confirm that the intentional coverage of the CA should not be considered an "innocent" procedure. On the other hand, in these circumstances any urgent surgical reintervention should not be dictated solely by blood test.

The distal landing zone at the supramesenteric border raised another important concern, which is the sealing 
TABLE 5. Thoracic endovascular aortic repair with intentional coverage of the celiac artery and supramesenteric distal sealing zone: Literature summary

\begin{tabular}{|c|c|c|c|c|c|c|c|c|c|c|c|}
\hline Author, (reference) & Cases (n) & $\begin{array}{c}\text { Incidence } \\
(\% / \text { TEVARs })\end{array}$ & $\begin{array}{c}\text { In-hospital } \\
\text { mortality (\%) }\end{array}$ & $\begin{array}{l}\text { SCI } \\
(\%) \\
\end{array}$ & $\begin{array}{c}\text { Visceral } \\
\text { ischemia } \\
(\%)\end{array}$ & $\begin{array}{c}\text { Follow-up } \\
(\mathrm{mo})\end{array}$ & $\begin{array}{l}\text { Survival } \\
(\% \text { at } 1 \text { y })\end{array}$ & $\begin{array}{c}\text { Redo } \\
(\%)\end{array}$ & $\begin{array}{l}\text { T1b } \\
(\%)\end{array}$ & $\begin{array}{c}\text { ORC } \\
(\%)\end{array}$ & $\begin{array}{c}\text { ARM } \\
(\%)\end{array}$ \\
\hline Siegenthaler and colleagues ${ }^{8}$ & 12 & 3.2 & n.e. & 0 & 0 & 17 & $80 \%$ & n.e. & n.e. & 0 & n.e. \\
\hline Brinster and colleagues ${ }^{9}$ & 6 & 2 & 0 & 0 & 0 & 30.5 & 100 & 33.3 & 16.6 & 0 & 0 \\
\hline Rose and colleagues ${ }^{10}$ & 18 & 4.9 & 6 & 11 & 11 & 38 & 78 & 27 & 11 & 5.5 & 0 \\
\hline Kato and colleagues $^{11}$ & 5 & n.e. & $0 *$ & 0 & 0 & 20.7 & n.e. & 20 & 20 & 0 & 0 \\
\hline Waldenberger and colleagues $^{12}$ & 10 & n.e. & 10 & 0 & 0 & 21 & 90 & 0 & 10 & 0 & 0 \\
\hline Mehta and colleagues ${ }^{13}$ & 31 & 13.5 & 6 & 6 & 6 & 15 & n.e. & 16 & 6 & 0 & 0 \\
\hline von Allmen and colleagues ${ }^{19}$ & 5 & 2.5 & 20 & 0 & 20 & 13 & $80 \%$ & 0 & 0 & 0 & 0 \\
\hline Belenky and colleagues ${ }^{21}$ & 7 & n.e. & 0 & 0 & 0 & n.e. & $86 \%$ & 42.8 & 14.3 & 0 & 0 \\
\hline Leon and colleagues ${ }^{22}$ & 16 & 3.7 & 18.7 & 12.5 & 6.25 & 8.7 & n.e. & 0 & 0 & 0 & 0 \\
\hline Delle and colleagues ${ }^{23}$ & 9 & 7.5 & 0 & 11.1 & 0 & $13-56$ & $100 \%$ & 0 & 0 & 0 & 0 \\
\hline
\end{tabular}

, Number; TEVAR, thoracic endovascular aortic repair; SCI, spinal cord ischemia; Redo, aortic reintervention; $T 1 b$, type $1 \mathrm{~b}$ endoleak occurrence; $O R C$, open repair conversion; $A R M$, aortic-related mortality; n.e., not possible to be extrapolated.

durability of this strategy because of the potential development of type $1 \mathrm{~b}$ endoleak. Specific technical details have been infrequently specified in previous reports, but to use this technical strategy, one should take into account 2 aspects of this distal sealing zone: First, this segment of visceral aorta is short but frequently tapered at the origin of the SMA. Second, the oversize cutoff for visceral artery overstenting in a TAAA treated with a standard SG is a different concept than graft replacement during OR. Because of this morphologic characteristic and oversizing with the currently available SGs, a distal seal has been accomplished in most type 1 and 5 TAAAs, which would have invariably needed more extensive visceral graft replacement during OR. ${ }^{8}$ Although type $1 \mathrm{~b}$ endoleak was never detected in our series, it was reported in $5.2 \%$ of the published cases: however, none presented with rupture and almost all endoleaks were successfully sealed off with an SG extension without additional mortality. ${ }^{9-13,21}$

Another potential problem when the distal landing zone approximating the upper limit of the SMA could be the onset of abdominal angina during the follow-up. In the published reports of TEVAR with intentional CA coverage and supramesenteric distal landing zone, abdominal angina was determined by distal migration of the SG or the partial coverage of the SMA origin by a stent strut of the SG. ${ }^{10,12,13}$ This event did not occur in our experience; however, in the rare cases in which it occurred, SMA stenosis was effectively treated with direct stenting and led to the complete resolution of the symptoms. Nonetheless, any subsequent mesenteric bypass surgery would not be precluded if another failure eventually occurs.

Regardless of the strategy adopted, patients with extent type 1 and 5 TAAA need extensive aortic treatment and are at high risk for SCI. Greenberg and colleagues ${ }^{6}$ reported an SCI hazard of 21 after TEVAR in these types of TAAAs.
Intercostal artery occlusion may not be sufficient per se to induce $S C I$, but those between $\mathrm{T}_{8}$ and $\mathrm{L}_{2}$ may play a critical role for the spinal perfusion. ${ }^{29}$ Even if our technical strategy may restrict the aortic coverage when compared with open/ hybrid/branched repair, in these types of TAAAs the coverage of this critical area is still essential. In our series, SCI is still substantial at $6 \%$ despite the best efforts to refine treatment strategy and the use of technical adjuncts. This is higher than the mean $4.6 \%$ by reviewing series enrolling more than 10 cases of intentional coverage of the CA, but neither aortic disease extent nor aortic coverage length was clearly reported in that experiences. ${ }^{8,10,12,13}$ In regard to SCI, a staged approach has been proposed to limit the ischemic insult when extensive aortic coverage is planned. ${ }^{29,30}$ We did not test this alternative strategy. This approach lacks strong evidence so far, but because of the encouraging results, it deserves attention for a possible application.

This technical strategy is not the only one we used for TAAA repair: OR, hybrid reconstructions with visceral vessels debranching, and total endovascular solution with fenestrations or parallel grafts have been tailored accordingly to the operative risk of the patient and the aortic disease. Although satisfactory results have been reported with all the alternative techniques, no full comparative analyses exist. ${ }^{6,24,26}$ Of the only 2 series that included hybrid TAAA repair and TEVAR with the intentional coverage of the CA, the results obtained by Siegenthaler and colleagues ${ }^{8}$ with isolated TEVAR highlighted the importance of the minimally possible invasiveness to obtain the least possible morbidity.

\section{Study Limitations}

First, this is a retrospective study, and the cohort is small in numbers. Second, the study has a sampling bias: OR and 
hybrid, fenestrated, or parallel SGs arms were not included for comparison because of the small number of patients in each treatment arm, but this reflects the careful selection process for this type of procedure. Last, multivariate analysis was not performed, but it would have been misleading because of the cohort size. Despite these limitations, inclusion criteria make the cohort homogeneous, the compliance to follow-up was high, and outcomes adhered systematically to the proposed guidelines that compare well with those of other studies.

\section{CONCLUSIONS}

TEVAR with intentional occlusion of the CA and supramesenteric distal landing zone to treat extent type 1 and 5 TAAAs showed encouraging results in selected patients at high risk for OR. In-hospital mortality was better than expected by score prediction, visceral ischemic injury was evident only on an enzymatic level, and follow-up survival is comparable to OR. At midterm follow-up, neither endoleak development nor aortic reintervention was related to the inadequate distal landing zone. Larger cohort or comparative experiences comprising all the different techniques to treat these TAAAs are expected for more comprehensive analyses. Nevertheless, this is a technical strategy that should be contemplated as a possible valid alternative in selected patients with extent type 1 and 5 TAAAs.

\section{Conflict of Interest Statement}

Authors have nothing to disclose with regard to commercial support.

Marco Franchin, MD, is a PhD student of the "Biotechnology, Biosciences, and Surgical Technology" course at Insubria University in Varese.

\section{References}

1. Gopaldas RR, Huh J, Dao TK, LeMaire SA, Chu D, Bakaeen FG, et al. Superior nationwide outcomes of endovascular versus open repair for isolated descending thoracic aortic aneurysm in 11,669 patients. J Thorac Cardiovasc Surg. 2010; 140:1001-10.

2. Estrera AL, Sandhu HK, Charlton-Ouw KM, Afifi RO, Azizzadeh A, Miller CC III, et al. A quarter century of organ protection in open thoracoabdominal repair. Ann Surg. 2015;262:660-8.

3. Coselli JS, LeMaire SA, Preventza O, de la Cruz KI, Cooley DA, Price MD, et al. Outcomes of 3309 thoracoabdominal aortic aneurysm repairs. J Thorac Cardiovasc Surg. 2016;151:1323-38.

4. Murana G, Castrovinci S, Kloppenburg G, Yousif A, Kelder H, Schepens M, et al. Open thoracoabdominal aortic aneurysm repair in the modern era: results from a 20-year single-centre experience. Eur J Cardiothorac Surg. 2016;49: 1374-81.

5. Cowan JA Jr, Dimick JB, Henke PK, Huber TS, Stanley JC, Upchurch GR Jr. Surgical treatment of intact thoracoabdominal aortic aneurysms in the United States: hospital and surgeon volume-related outcomes. J Vasc Surg. 2003;37: 1169-74.

6. Greenberg RK, Lu Q, Roselli EE, Svensson LG, Moon MC, Hernandez AV, et al. Contemporary analysis of descending thoracic and thoracoabdominal aneurysm repair: a comparison of endovascular and open techniques. Circulation. 2008; 118:808-17.
7. Drinkwater SL, Böckler D, Eckstein H, Cheshire NJ, Kotelis D, Wolf O, et al. The visceral hybrid repair of thoraco-abdominal aortic aneurysms-a collaborative approach. Eur J Vasc Endovasc Surg. 2009;38:578-85.

8. Siegenthaler MP, Weigang E, Brehm K, Euringer W, Baumann T, Uhl M, et al. Endovascular treatment for thoracoabdominal aneurysms: outcomes and results. Eur J Cardiothorac Surg. 2008;34:810-9.

9. Brinster CJ, Szeto WY, Bavaria JE, Woo EY, Fairman RM, Jackson BM Endovascular repair of extent I thoracoabdominal aneurysms with landing zone extension into the aortic arch and mesenteric portion of the abdominal aorta. J Vasc Surg. 2010;52:460-3.

10. Rose MK, Pearce BJ, Matthews TC, Patterson MA, Passman MA, Jordan WD Outcomes after celiac artery coverage during thoracic endovascular aortic aneurysm repair. J Vasc Surg. 2015;62:36-42.

11. Kato M, Motoki M, Isaji T, Suzuki T, Kawai Y, Ohkubo N. Spinal cord injury after endovascular treatment for thoracoabdominal aneurysm or dissection. Eur J Cardiothorac Surg. 2015;48:571-7.

12. Waldenberger P, Bendix N, Petersen J, Tauscher T, Glodny B. Clinical outcome of endovascular therapeutic occlusion of the celiac artery. J Vasc Surg. 2007;46: 655-61.

13. Mehta M, Darling RC III, Taggert JB, Roddy SP, Sternbach Y, Ozsvath KJ, et al Outcomes of planned celiac artery coverage during TEVAR. J Vasc Surg. 2010; 52:1153-8.

14. Etz CD, Weigang E, Hartert M, Lonn L, Mestres CA, Di Bartolomeo R, et al Contemporary spinal cord protection during thoracic and thoracoabdominal aortic surgery and endovascular aortic repair: a position paper of the vascular domain of the European Association for Cardio-Thoracic Surgery. Eur J Cardiothorac Surg. 2015;47:943-57.

15. Society of Thoracic Surgeons. Committee to develop a national database for thoracic surgeons. Definitions of terms of the Society of Thoracic Surgeons national cardiac surgery database. Ann Thorac Surg. 1994;58:271-3.

16. Fillinger MF, Greenberg RK, McKinsey JF, Chaikof EL. Society for Vascular Surgery Ad Hoc Committee on TEVAR Reporting Standards. Reporting standards for thoracic endovascular aortic repair (TEVAR). J Vasc Surg. 2010; 52:1022-33.

17. Turina MI, Shennib H, Dunning J, Cheng D, Martin J, Muneretto C, et al EACTS/ESCVS committee. EACTS/ESCVS best practice guidelines for reporting treatment results in the thoracic aorta. Eur J Cardiothorac Surg. 2009:35:927-30.

18. Nashef SA, Roques F, Sharples LD, Nilsson J, Smith C, Goldstone AR, et al EuroSCORE II. Eur J Cardiothorac Surg. 2012;41:734-44.

19. von Allmen RS, Weiss S, Tevaearai HT, Kuemmerli C, Tinner C, Carrel TP, et al. Completeness of follow-up determines validity of study findings: results of a prospective repeated measures cohort study. PLoS One. 2015;10:e14081.

20. Hyhlik-Dürr A, Geisbüsch P, von Tengg-Kobligk H, Klemm K, Böckler D. Intentional overstenting of the celiac trunk during thoracic endovascular aortic repair: preoperative role of multislice CT angiography. J Endovasc Ther. 2009; 16:48-54.

21. Belenky A, Haddad M, Idov I, Knizhnik M, Litvin S, Bachar GN, et al. Celiac trunk embolization as a means of elongating short distal descending thoracic aortic aneurysm necks, prior to endovascular aortic repair. Cardiovasc Intervent Radiol. 2009;32:923-37.

22. Leon LR Jr, Mills JL Sr, Jordan W, Morasch MM, Kovacs M, Becker GJ, et al. The risks of celiac artery coverage during endoluminal repair of thoracic and thoracoabdominal aortic aneurysms. Vasc Endovascular Surg. 2009;43: 51-60.

23. Delle M, Lönn L, Henrikson O, Formgren J, Vogt K, Falkenberg M. Celiac trunk coverage in endovascular aneurysm repair. Scand J Surg. 2010;99: 226-9.

24. Ferrer C, Cao P, De Rango P, Tshomba Y, Verzini F, Melissano G, et al. A propensity-matched comparison for endovascular and open repair of thoracoabdominal aortic aneurysms. J Vasc Surg. 2016;63:1201-7.

25. Schaffer JM, Lingala B, Miller DC, Woo YJ, Mitchell RS, Dake MD. Midterm survival after thoracic endovascular aortic repair in more than 10,000 Medicare patients. J Thorac Cardiovasc Surg. 2015;149:808-20.

26. Patel R, Conrad MF, Paruchuri V, Kwolek CJ, Chung TK, Cambria RP Thoracoabdominal aneurysm repair: hybrid versus open repair. J Vasc Surg. 2009;50:15-22.

27. Patel HJ, Shillingford MS, Williams DM, Upchurch GR Jr, Dasika NL, Prager RL, et al. Survival benefit of endovascular descending thoracic aortic repair for the high-risk patient. Ann Thorac Surg. 2007;83:1628-33. 
28. Jim J, Caputo FJ, Sanchez LA. Intentional coverage of the celiac artery during thoracic endovascular aortic repair. J Vasc Surg. 2013; 58:270-5.

29. Etz CD, Zoli S, Mueller CS, Bodian CA, Di Luozzo G, Lazala R, et al. Staged repair significantly reduces paraplegia rate after extensive thoracoabdominal aortic aneurysm repair. J Thorac Cardiovasc Surg. 2010; 139:1464-72.
30. O'Callaghan A, Mastracci TM, Eagleton MJ. Staged endovascular repair of thoracoabdominal aortic aneurysms limits incidence and severity of spinal cord ischemia. J Vasc Surg. 2015;61:347-54.

Key Words: celiac artery coverage, spinal cord ischemia, thoracoabdominal aortic aneurysm 
APPENDIX.

STENT-GRAFT

Excluder/TAG/C-TAG (WL Gore \& Associates, Flagstaff, Ariz)

Talent/Valiant/Captivia (Medtronic Vascular, Santa Rosa, Calif)

Relay (Bolton Medical, Sunrise, Fla)

\section{LEFT SUBCLAVIAN ARTERY MANAGEMENT}

Occlusion plug, Amplatzer (St Jude Medical, St Paul, Minn)
PERIPHERAL STENT

Renal, Genesis Blue (Cardinal Health, Baar, Switzerland)

Iliac, S.M.A.R.T (Cardinal Health)

CONVENTIONAL SURGICAL GRAFT

Bypass, Propaten (WL Gore \& Associates)

CEREBROSPINAL FLUID DRAINAGE

Duet (Medtronic Vascular) 